\begin{tabular}{cc}
\hline International Journal of Engineering \& Technology, $7(3.21)(2018) 1-4$ \\
SPC \\
Website: ww. weriencepubco.com/index.php/IJET \\
Research paper
\end{tabular}

\title{
Emotional Intelligence and Transformational Leadership Among Managers in Manufacturing Companies
}

\author{
Shiau Wei Chan ${ }^{1 *}$, Siti Sarah Omar ${ }^{2}$, Ramlan, R. ${ }^{3}$, Md Fauzi Ahmad ${ }^{4}$, Izzuddin Zaman ${ }^{5}$, Nuratiqah Idrus $^{6}$ \\ ${ }^{1,2,3,4,6}$ Faculty of Technology Management and Business, Universiti Tun Hussein Onn Malaysia, 86400 Batu Pahat, Johor, Malaysia \\ ${ }^{5}$ Faculty of Mechanical and Manufacturing Engineering, Universiti Tun Hussein Onn Malaysia, 86400 Batu Pahat, Johor, Malaysia \\ *Corresponding author E-mail: swchan@uthm.edu.my
}

\begin{abstract}
Despite the fact that numerous studies have been conducted on Emotional Intelligence (EI) and Transformational Leadership (TL), the relationship between EI and TL is yet to be identified. The purpose of this research is to determine the relationship between EI and TL skills among managers in manufacturing companies in Batu Pahat. In this research, a survey questionnaire was administered to fifty managers. Pearson correlation coefficient analysis was employed to test the correlation among variables, including Perceiving Emotion, Facilitating Thought, Understanding Emotion, and Managing Emotion with TL skills. The outcome was that a positive relationship was found between EI and TL skills. This quantitative research is important in providing management with better information regarding the relationship between EI and TL skills among managers so that managers can learn and improve their functions.
\end{abstract}

Keywords: Emotional intelligence; transformational leadership; manufacturing companies.

\section{Introduction}

Recent studies have shown that EI has an influence in TL. However, there has been widespread uncertainty about the link between EI and TL outcomes and many studies have failed to find notable relationships between EI and TL in particular (1-3). The EI research has little empirical evidence and the relationship between EI and TL is still not fully identified. What is more concerning is that it is seen by many as vitally important for leaders to be emotionally intelligent for organizational success, but there is not much methodologically defensible evidence for this requirement. In addition, while studies have been conducted to investigate the relationship between EI and TL in foreign countries, there is a lack of research on this issue in Malaysia. Therefore, this study seeks to fill these gaps and addresses this issue in specific manufacturing companies in Batu Pahat. Within the company context, it is crucial to identify the existence of a relationship between TL and EI.

The impact of leadership is a vital factor of productivity in any organization. Transformational leadership (TL) is a leadership style that refers to the process of building commitment to the organization's objectives and empowering followers to accomplish these objectives $(4,5)$. explains that transformational leadership philosophies emerge from the researcher's pursuit of the emotional and denotative facets of leadership impact. On the other hand, the phrase 'Emotional Intelligence (EI)' was used by, (6), and indicates the degree of insight with which people perceive feelings, inspire and regulate emotions in life. As leadership style and EI often predict the quality of employees' performance, (6) suggest that managers who are in charge of the process must possess good leadership traits and be emotionally intelligent. These people are able to get things done by influencing others to execute the necessary actions to achieve individual and management goals.

\section{Literature Review}

Emotional Intelligence, also called Emotional Quotient (EQ), refers to 'the ability to perceive accurately, appraise, and express emotion; the ability to access and/or generate feelings when they facilitate thought; the ability to understand emotion and emotional knowledge; and the ability to regulate emotions to promote emotional and intellectual growth' (7). EI has its roots in the concept of social intelligence, introduced by Thorndike in 1920 (8), which refers to the ability to understand others and to act wisely in human relations. This intelligence includes self-awareness, empathy and handling interpersonal relationships which rebuild and rehabilitate the core of emotional intelligence, which is essential for the social intelligence dimension (9). construction of EI comprises an aptitude for: appraising and expressing emotions in self and others; regulating emotions in self and others; and using emotions in adaptive ways.

Perceiving emotions concerns the ability to perceive feelings in self and others. Emotional perception involves fixating on, and accurately decoding, emotional signals in facial expression, tone of voice, and artistic expressions (6). Besides, facilitating Thought is the ability to employ feelings to enhance mental processing. As such, this ability can be harnessed for more efficacious problemsolving, reasoning, decision-making, and creative endeavours (6). Furthermore, understanding emotions deals with a person's ability to understand the causes and consequences of emotions (7). Moreover, emotional management refers to the proactive evaluation and management of one's own and other people's emotions (9).

TL theory has derived over time from the historical evolution of leadership theory from its initial focus on Great Man and trait 
theory to the contemporary study of transformational leadership offered. Transformational leaders germinate positive relationships with subordinates in order to fortify employee and organizational operation. Besides, transformational leaders improve the performance of their followers by attracting them to higher ideals and values such as autonomy, equity, serenity, and parity (10). On the other hand, individualized consideration deals with underlying TL demeanour of addressing individuals as crucial contributors to the work environment. Leaders who utilize this style of leadership show consideration for their workers' needs and are able to boost and train the development of an encouraging workplace environment(10).

According to Burke and Collins (11), transformational leaders accomplish these results in one or more of the following ways, which comprise one of four interrelated elements of TL: (i) Idealized Influence is behaviour that arouses vigorous follower emotions and identification with the leader; (ii) Intellectual Stimulation is behaviour that increments cognizance of problems and influences followers to view problems from an incipient perspective; (iii) Individualized Consideration includes providing support, encouragement, and coaching to followers; (iv) Inspirational Motivation includes communicating an appealing vision, utilizing symbols to focus subordinate effort, and modelling felicitous behaviour.

Numerous studies had been conducted to investigate the relationship between emotional intelligence and transformational leadership. In the study of Barling et al.(12), positive relationships were found between EI and three aspects of TL (idealised influence, inspirational motivation, individualised consideration)(13). found significant correlations between some components of TL (idealized influence, inspirational motivation, individualized consideration) and the EI subscales. Besides, the finding from the study of Gardner and Stough (14), indicated that EI correlated strongly with all components of TL, with the components of understanding of emotions (external) and emotional management being the best predictors of this type of leadership style.

The study of (15) demonstrated that leaders who reported higher ratings of EI were perceived by their followers as being higher in TL and more efficacious. According to Duckett and MacFarlane (15), there was a strong connection between the theory of EI and TL: however, distinctions between the idealised and genuine EI scores were mainly located in transactional capabilities. Furthermore, (16) found a significant predictive relationship $(p<.05)$ between TL style and EI. Leban and Zulauf (17), demonstrated linkages between project managers' EI abilities and TL styles under a systems thinking and project management approach. The results of the study found that a project manager's TL style has a positive impact on genuine project performance, and that emotional insight contributes to a project manager's TL style and subsequent genuine project performance.

Moreover, (18). examined how leaders' emotional apperception ability and personality characteristics influenced the performance of TL behaviour. Emotional apperception, positive affectivity, and agreeableness positively predicted such behaviour. They additionally provided construct validity evidence for TL behaviour by demonstrating differing effects of these antecedents on contingent reward behaviour. Furthermore, the study of Downey et al., (19), revealed that female managers displaying transformational leadership traits were more liable to exhibit higher levels of EI and intuition than female managers displaying less transformational leadership traits. A study done by (20) showed significant differences across the different disciplines and illustrated that emotional intelligence and gender roles predict TL.

Hence, the following hypotheses are suggested in this study:

H1: Perceiving Emotions is positively related to transformational leadership.

$\mathrm{H} 2$ : Facilitating Thought is positively related to transformational leadership.

H3: Understanding Emotions is positively related to transformational leadership.
H4: Managing Emotions is positively related to transformational leadership.

\section{Material and Methods}

\subsection{Respondents and Procedure}

There were 50 managers involved in this study. They were chosen randomly from the manufacturing companies in Batu Pahat, Malaysia. Among them, $44(88 \%)$ were male and $6(12 \%)$ female. Based on age, $14 \%$ were aged between 26 and 35 years, $30 \%$ were aged between 36 and 45 years, $44 \%$ were aged between 44 and 55 years, and $12 \%$ were aged 56 years and over. More than half of the respondents $(56 \%)$ had more than ten years of work experience, followed by $42 \%$ who had between six and nine years of work experience. The rest had between two and five years of work experience. Twenty-nine of the managers $(58 \%)$ came from management departments, while six $(12 \%)$ were from finance departments and four $(8.5 \%)$ were from operation departments; the remaining eleven of them came from other departments.

A quantitative approach was used for this study. Quantitative research involves explaining phenomena by collecting numerical data that are analyzed using mathematically based methods, particularly statistics (21). Quantitative research is well suited for the testing of theories and hypotheses. In this study, data were collected through questionnaires during the process of gathering and measuring information on variables. The data collection procedure began in September 2015. A pre-test was conducted, during which ten sets of survey questions were distributed in one manufacturing company in Batu Pahat. Then the main questionnaires were distributed and collected three weeks later during visits to the selected companies.

The collected data were analyzed using IBM Statistical Package for the Social Sciences (SPSS) version 16.0. The data were analyzed using descriptive and inferential statistics. Descriptive statistics such as frequencies and percentages were used to measure the percentage of returned questionnaires and also to describe the respondents' profiles. Correlations were used for inferential statistics to determine the relationships between independent and dependent variables, namely Emotional Intelligence and Transformational Leadership behavior.

\subsection{Measures}

\subsubsection{Emotional Intelligence}

The emotional intelligence questionnaire was adapted from the ability model conceptualized by (7). It consisted of four dimensions (perceiving emotion, facilitating thought, understanding emotion and managing emotion) to measure EI. This thirty-item scale uses a five-point Likert scale ranging from $1=$ strongly disagree to $5=$ strongly agree. This instrument has been shown to have excellent internal consistency according to the guidelines set by George and Mallery (22), as its Cronbach Alpha score is 0.901 .

\subsubsection{Transformational Leadership}

In this study, the transformational leadership questionnaire was adopted from Bass's Multifactor Leadership Questionnaire (MLQ). This twenty-item questionnaire is based on a five-point Likert scale ranging from $1=$ strongly disagree to $5=$ strongly agree. The Cronbach Alpha for this instrument is 0.954. Hence, its internal consistency is judged as excellent, according to the guidelines set by (22). 


\section{Results}

Normality testing was conducted to determine whether or not the study population was normally distributed. Based on the tests carried out using the Kolmogorov-Smirnov method, both EI and TL displayed significant values of $p>0.05$. Therefore, it can be concluded that the data in this study are normally distributed. Therefore, Pearson correlation was used to measure the significance of linear bivariate correlation between independent and dependent variables, thereby, achieving the objectives of this study (23). Variable association refers to a wide variety of coefficients which measure the strength of a relationship. In this study, variables relating to perceiving emotions and transformational leadership were significantly correlated, with a strong positive correlation (0.788). This result is consistent with the findings reported by Barling et al., (12), who found a positive relationship between EI and TL. Besides, transformational leadership style and facilitating thought variables were significantly correlated, with a strong positive correlation (0.783), which is compatible with the results found in a study by (13). Significant correlations between some components of TL were confirmed.

Furthermore, variables relating to understanding emotions and transformational leadership were significantly correlated, with a strong positive correlation (0.861). This is is in accordance with findings reported by Gardner and Stough (14), where EI correlated highly with all components of TL. Moreover, transformational leadership and variables relating to understanding and managing emotions were significantly correlated, with a strong positive correlation (0.937). A positive relationship was found between EI and TL. This suggests that the abilities encompassed by EI are intrinsically related to the role of the transformational leader.

\section{Discussion and Conclusion}

The analysis indicates that there is a relationship between EI and TL in manufacturing companies in Batu Pahat. The linkages between EI and the ability to use the TL style are found to be positive in these companies: this suggests that qualified managers are those who use emotional intelligence in order to create positive performance. The result of correlation analysis in assessing the variables or the empirical relationship between emotional intelligence supports the assumption hypothesized in this study. The positive association between emotional intelligence and the transformational leadership style of managers supports the general claim worldwide, as discussed in the literature, and the concept development of emotional intelligence as interaction in transforming managers.

There are some recommendations for future studies. The present study's sample size of 50 might not be enough to support the claim. A larger pilot study should be conducted to reveal issues with understanding the directions and data collection. To increase the response rate, the size of future samples should be maximized. In addition, future research should include a wider range of organizations and locations in Malaysia. On the other hand, according to the theory, emotional intelligence can be developed throughout life. Thus, it is suggest conducting more training courses on EI for managers which would contribute to their performance (24). A longitudinal study that incorporates a development program along with pre-post-tests would be the best way to adequately assess development and improvement in an individual's level of emotional intelligence.

Various amounts of research on EI and studies on TL have been conducted, but there has been relatively little focus on the manufacturing industry. This study contributes to the existing literature by providing empirical evidence on the relationship between EI and TL among managers in manufacturing companies in Batu Pahat, thus helping to close the gap in knowledge. This study is also important, particularly in providing management with better information regarding the relationship between managers' EI scores and their TL skills so that the managers can learn and im- prove their functions. It is anticipated that the findings will be useful for improving the working culture and enhancing managers' leadership and employees' followership behavior.

\section{Acknowledgment}

This work was supported by Universiti Tun Hussein Onn Malaysia under Grant No. U431.

\section{References}

[1] Brown FW, Bryant SE, Reilly MD. Does emotional intelligence-as measured by the EQI-influence transformational leadership and/or desirable outcomes? Leadership \& Organization Development Journal. 2006;27(5):330-51.

[2] Moss S, Ritossa D, Ngu S. The effect of follower regulatory focus and extraversion on leadership behavior: The role of emotional intelligence. Journal of Individual Differences. 2006;27(2):93-107.

[3] Weinberger LA. An examination of the relationship between emotional intelligence and leadership style. Online Submission. 2004.

[4] Shamir B, House RJ, Arthur MB. The motivational effects of charismatic leadership: A self-concept based theory. Organization science. 1993;4(4):577-94

[5] Johnson WB. Transformational supervision: When supervisors mentor. Professional Psychology: Research and Practice. 2007;38(3):259.

[6] Mayer JD, Salovey P, Caruso DR. TARGET ARTICLES:" emotional Intelligence: theory, findings, and implications". Psychological inquiry. 2004;15(3):197-215.

[7] Mayer J. What is emotional intelligence: In P. Salovey and D. Sluyter (Eds.), Emotional development, emotional literacy, and emotional intelligence. New York: Basic Books; 1990.

[8] Wilding C. Emotional intelligence: Hachette UK; 2017.

[9] Salovey P, Mayer J. Emotional intelligence. Imagina-tion, Cognition, and Personality, 9, 185-211. Salovey1859Imagination. Cognition, and Personality1990. 1990.

[10] Sarros JC, Santora JC. The transformational-transactional leadership model in practice. Leadership \& organization development journal. 2001;22(8):383-94.

[11] Burke S, Collins KM. Gender differences in leadership styles and management skills. Women in Management Review. 2001;16(5):244-57.

[12] Barling J, Slater F, Kevin Kelloway E. Transformational leadership and emotional intelligence: An exploratory study. Leadership \& Organization Development Journal. 2000;21(3):157-61.

[13] Palmer B, Walls M, Burgess Z, Stough C. Emotional intelligence and effective leadership. Leadership \& Organization Development Journal. 2001;22(1):5-10.

[14] Gardner L, Stough C. Examining the relationship between leadership and emotional intelligence in senior level managers. Leadership \& organization development journal. 2002;23(2):68-78.

[15] Duckett H, Macfarlane E. Emotional intelligence and transformational leadership in retailing. Leadership \& Organization Development Journal. 2003;24(6):309-17.

[16] Mandell B, Pherwani S. Relationship between emotional intelligence and transformational leadership style: A gender comparison. Journal of business and psychology. 2003;17(3):387404.

[17] Leban W, Zulauf C. Linking emotional intelligence abilities and transformational leadership styles. Leadership \& Organization Development Journal. 2004;25(7):554-64.

[18] Rubin RS, Munz DC, Bommer WH. Leading from within: The effects of emotion recognition and personality on transformational leadership behavior. Academy of Management Journal. 2005;48(5):845-58

[19] Downey L, Papageorgiou V, Stough C. Examining the relationship between leadership, emotional intelligence and intuition in senior female managers. Leadership \& Organization Development Journal. 2006;27(4):250-64

[20] Lopez-Zafra E, Garcia-Retamero R, Martos MPB. The relationship between transformational leadership and emotional intelligence from a gendered approach. The Psychological Record. 2012;62(1):97.

[21] Aliaga M, Gunderson B. Interactive statistics. Saddle River. 2000;35:3-15. 
[22] George D, Mallery P. SPSS for Windows step by step: A simple guide and reference. 11.0 update. wps. ablongman. com/wps/media/objects/385. George 4answers pdf. 2003

[23] Sekaran U, Bougie R. Research methods for business: A skill building approach: John Wiley \& Sons; 2016.

[24] Chan SW, Ahmad M, Ngadiman Y, Omar SS. Emotional Intelligence and Job Performance: A Qualitative Meta-Analysis. Advanced Science Letters. 2015;21(6):2050-4. 